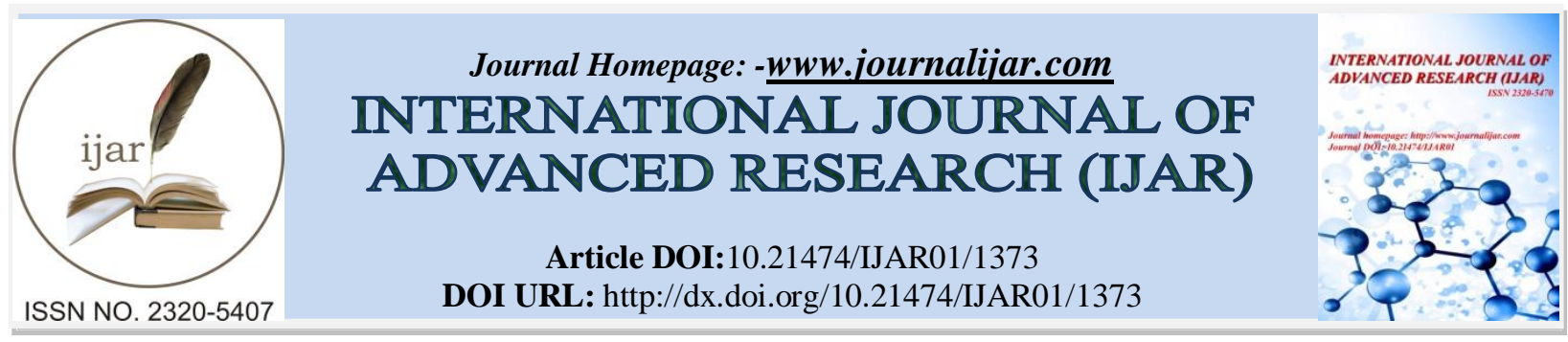

RESEARCH ARTICLE

\title{
NEUTRON REPULSION- SOCIAL COSTS FROM OVERLOOKING THIS POWER
}

\author{
* Oliver K. Manuel \\ CSSI Associate \& Emeritus Professor, University of Missouri, Cape Girardeau, MO 63701 USA
}

\section{Manuscript Info}

Manuscript History

Received: 15 June 2016

Final Accepted: 16 July 2016

Published: August 2016

Key words:-

Energy, Physics, Power, Sun, God,

Einstein

\section{Abstract}

The purpose of this paper is to allow the public to understand better, and reap benefits from, Einstein's 1905 discovery that rest mass $(\boldsymbol{m})$ is energy $(\boldsymbol{E})$ and to explain the chain of events in 1905-1945that obscuredknowledge of a power offering these benefits to all humanity:

1. Abundant energy to sustain human life and to advance human civilization;

2. A better understanding of the origin and evolution of the universe, the chemical elements, the solar system, and life on Earth; and

3. Empirical confirmation - in rest masses of ordinary atoms -of many earlier spiritual and scientific insights, including Aston's 1922 promise of "powers beyond the dreams of scientific fiction," Max Planck's 1944 assertion that the force creating atomic matter was guided by "a conscious and intelligent Mind" (commonly attributed to God), and Kuroda's 1945 insight into the "beginning of the world" from Hiroshima's destruction.

Copy Right, IJAR, 2016,. All rights reserved.

\section{Introduction:-}

Einstein (1905) reported mass $(\boldsymbol{m})$ is stored energy $(\boldsymbol{E})$, before it was known that atoms of the same element may have different atomic masses. Aston used the mass spectrograph to identify isotopes of several elements, measured and reported their masses as nuclear "packing fractions," and reported in the last paragraph of his Nobel Lecture (Aston, 1922) that these offer the human race command over "powers beyond the dreams of scientific fiction." Ten years later, Chadwick (1932) reported discovery of the neutron, "a proton and an electron in close combination." This explainedProut's 1815 hypothesis of hydrogen as a fundamental block, and Aston's confirmation ofonly whole integer values forall atomic mass numbers. Three years later, Weizsäcker (1935) developed the concept of nuclear "binding energy," based on the neutron-proton model of the nucleus. Bethe and Bacher (1936) used this neutronproton model of the nucleus to explain stationary states of nuclei. When Aston repeated his 1922 Nobel Lecture at the Imperial University of Tokyo on 13 June 1936, Kuroda (1992) noticed and commented on a misunderstanding of Aston's nuclear "packing fraction." This errorwill beillustratedbelow by comparing common disagreements between Aston's nuclear "packing fraction" and the Bethe-Weizsäcker concept of nuclear "binding energy." After Hahn and Strassman (1939) reported neutron-induced fission of uranium, scientists in other countries independently discovered and reported the number of secondary neutrons released and the possibility of inducing a self-sustaining chain of nuclear reactions in 1939 (Anderson et al., 1939; Hagiwara, 1939; Halbanet al., 1939; Zinn and Szilard, 1939). Bohr and Wheeler (1939) used the Bethe-Weizsäckermodel to proposetheCoulomb repulsionmodelof nuclear fission.

Corresponding Author:-Oliver K. Manuel.

Address:-CSSI Associate \& Emeritus Professor, University of Missouri, Cape Girardeau, MO 63701 USA. 
As WWII ended, Max Planck (1944) spoke of "a conscious and creative Mind" guidingthe force that makes and holds sub-atomic particles together.In ruins of Hiroshima in August 1945, Kuroda (1982) realized, "The sight before my eyes was just like the end of the world, but I also felt that the beginning of the world may have been just like this."

\section{Materials and Methods:-}

Materials and methods are essentially those used in several other papers published over the last sixteen years (Manuel, et al., 2000; Manuel, et al., 2002;Manuel, 2016a,b):Precise atomic rest mass data from the National Nuclear Data Center, Brookhaven National Laboratory are used to identify the major sources of energy in rest masses of atoms and to explain why neutron repulsion was overlooked in the historical development of nuclear energy.

\section{Results and Discussion:-}

The first figure shows rest masses of atoms, expressed as $1+f$ (Aston's packing fraction), as they appeared to Aston in 1922, before the neutron was known and the now popular semi-empirical formula for atomic masseswas developed in 1935-36 (https://en.wikipedia.org/wiki/Semi-empirical_mass_formula).

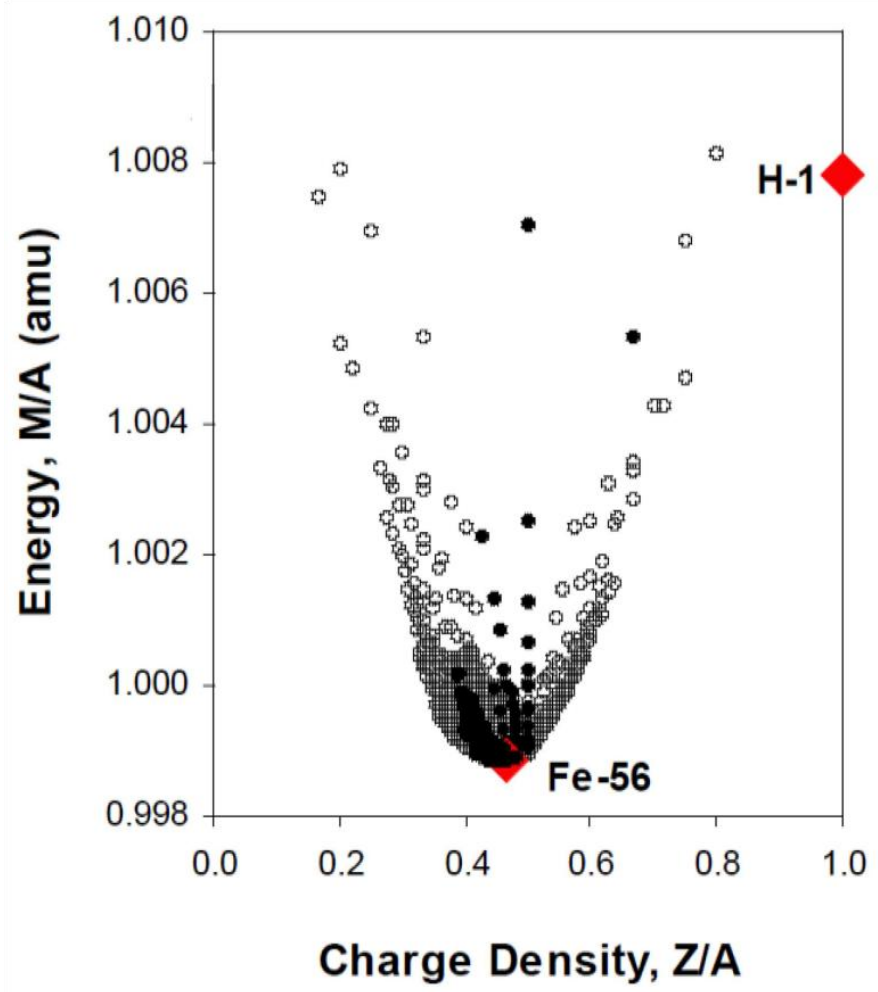

Figure 1:-The horizontal scale is charge density. The vertical scale is mass (energy) per nucleon, or $1+f$, where $f=$ Aston's nuclear "packing fraction." Atomic mass data points are filled for stable atoms; their range is shown by filled red symbols at Fe-56 and H-1. Open symbols identify unstable atoms.

Aston might have recognized evidence for neutron-, as well as, proton-repulsion in the symmetry of atomic rest mass data about values of $\mathrm{Z} / \mathrm{A} \sim 0.5$, butthe neutron was not discovered until a decade later, in 1932.

To understand why neutron repulsion was overlooked as the knowledge of nuclear energy advanced, Figure 1 illustrates Aston's view of rest mass data (Aston, 1922) before Chadwick (1932) discovered the neutron. The decrease in values of M/A as the charge density (Z/A) decreased from 1 to 0.5 might be explained by a decrease in Coulomb repulsion between positive charges. But Coulomb repulsion could not explain the mysterious, but unknown force that caused values of M/A to increase as the charge density (Z/A) decreased further, from 0.5 toward 0. The neutron was unknown, so Aston could not have possibly identified that force as "neutron repulsion" in 1922. 
That is probably why Aston (1922) instead spoke of thisas a mysterious force that offered the human race command over "powers beyond the dreams of scientific fiction."

After Chadwick (1932) discovered the neutron, the next figure shows how rest masses of atoms might have appeared to Weizsäcker (1935), Bethe and Bacher (1936) and Bohr and Wheeler (1939) as they attempted to explain variations in masses of atoms and the fission of uranium atoms when irradiated with neutrons, before the force of neutron-repulsion was recognized in the atomic rest mass data.

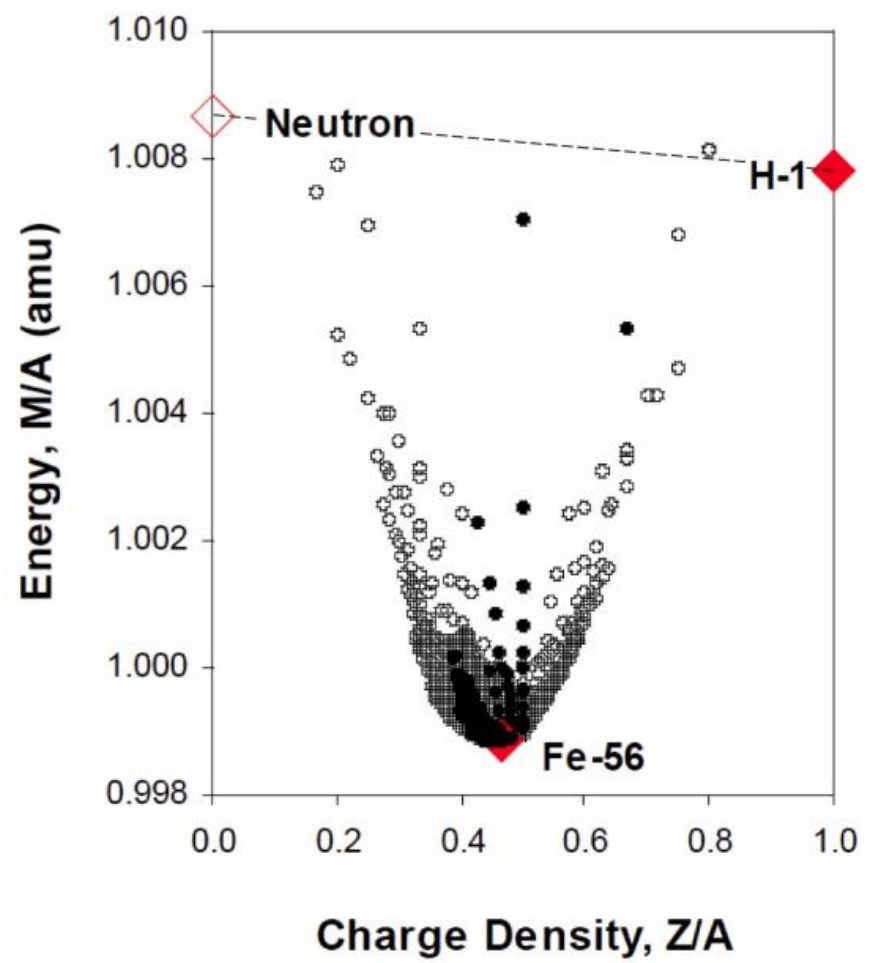

Figure 2:-The horizontal scale is charge density. Vertical distance of masses from the dashed line is Bethe-

Weizsäcker's “binding energy" per nucleon.

Bethe-Weizsäcker's "binding energy" is illustrated in Figure 2 by the vertical distance down from the dashed line to any mass data point. Because the neutron has greater mass than the hydrogen atom, this distance is deceptively high for neutron-rich atoms, and deceptively low for proton-rich atoms. That is why neutron-rich radioactive atoms, like ${ }^{3} \mathrm{H}$ and ${ }^{14} \mathrm{C}$, have higher calculated values of nuclear "binding energy" than their more stable decay products, ${ }^{3} \mathrm{He}$ and ${ }^{14} \mathrm{~N}$.

To explain further why neutron repulsion was over-looked as knowledge of nuclear energy advanced, the dashed line in Figure 2 shows subtle differences between Aston's definition of nuclear "packing fraction" (Aston, 1922) -a thermodynamic state that is experimentally $\underline{\text { measured }}-$ and Bethe-Weizsäcker's definition of nuclear "binding energy" - a thermodynamic path function that is calculated.

The third figure shows least-squares fitted mass parabolas to rest mass data at each mass number, A, with intercepts at $\mathrm{Z} / \mathrm{A}=0$ (blue) and $\mathrm{Z} / \mathrm{A}=1$ (red). 


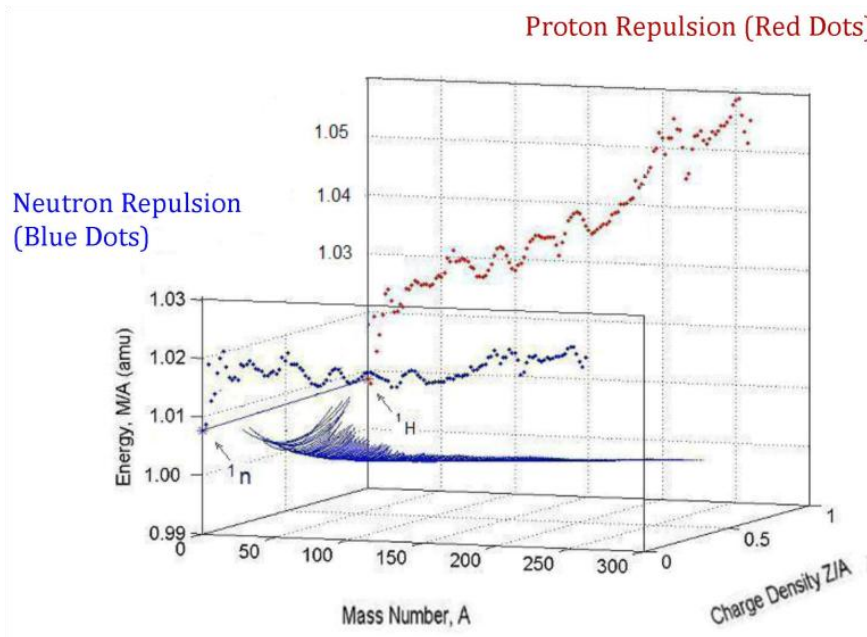

Figure 3:-The red dots, at $\mathrm{Z} / \mathrm{A}=1$, show energy (mass) from proton repulsion and blue dots, at $\mathrm{Z} / \mathrm{A}=0$, show energy (mass) from neutron repulsion.

Strong attractive forces between neutrons and protons produce low values of M/A in mass data points near Z/A 0.5 in Figure 1 and in Figure 2, and in the mass parabolas in Figure 3 (Manuel, 2016a)

Blue dots in Figure 3 are values of M/A calculated from mass parabolas for hypothetical atoms composed of neutrons only at $\mathrm{Z} / \mathrm{A}=0$. Neutron repulsion causes all values of $\mathrm{M} / \mathrm{A}$ (blue dots) to be higher that of the free neutron at $A=1$. Neutron repulsion is a strong, but short-range nuclear force (Manuel, 2016a).

Red dots in Figure 3 are values of M/A calculated from mass parabolas for hypothetical atoms composed of hydrogen only at $\mathrm{Z} / \mathrm{A}=1$. Proton repulsion causes values of $\mathrm{M} / \mathrm{A}$ (red dots) to be consistently higher that of hydrogen atoms at $\mathrm{A}=1$. Proton repulsion is long-range. Thus, the values of $\mathrm{M} / \mathrm{A}$ at $\mathrm{Z} / \mathrm{A}=1$ increase with mass number, A (Manuel, 2016a).

That is why neutron repulsion remains relatively unimportant in light atoms, when the nuclear core is neutron-proton pairs and the extra neutrons are at the nuclear surface, but neutron repulsion becomes increasingly important for heavier atoms, and at $\mathrm{A}=144 \mathrm{amu}$, Coulomb repulsion is strong enough to completely invert the nuclear structure. For A $<144 \mathrm{amu}$, the nuclear core is neutron-proton pairs and extra neutrons are on the nuclear surface. For A> 143 $\mathrm{amu}$, the nuclear core is neutrons and the nuclear surface is neutron-proton pairs (Manuel, 2016a).

Thus, the Bethe-Weizsäcker model of nuclear "binding energy"has obscured neutron repulsion, exaggerated proton repulsion and confirmed the validity of Kuroda's concern when a physicist asked, "What is meant by packing fraction?" after Astonhad lectured on nuclear "packing fractions" at the Imperial University of Tokyo on 13 June 1936 (Kuroda, 1992).

Finally, the fourth and final figure shows why neutron repulsion in the Sun's core is of interest to all humanity, and of special interest to scientists. 


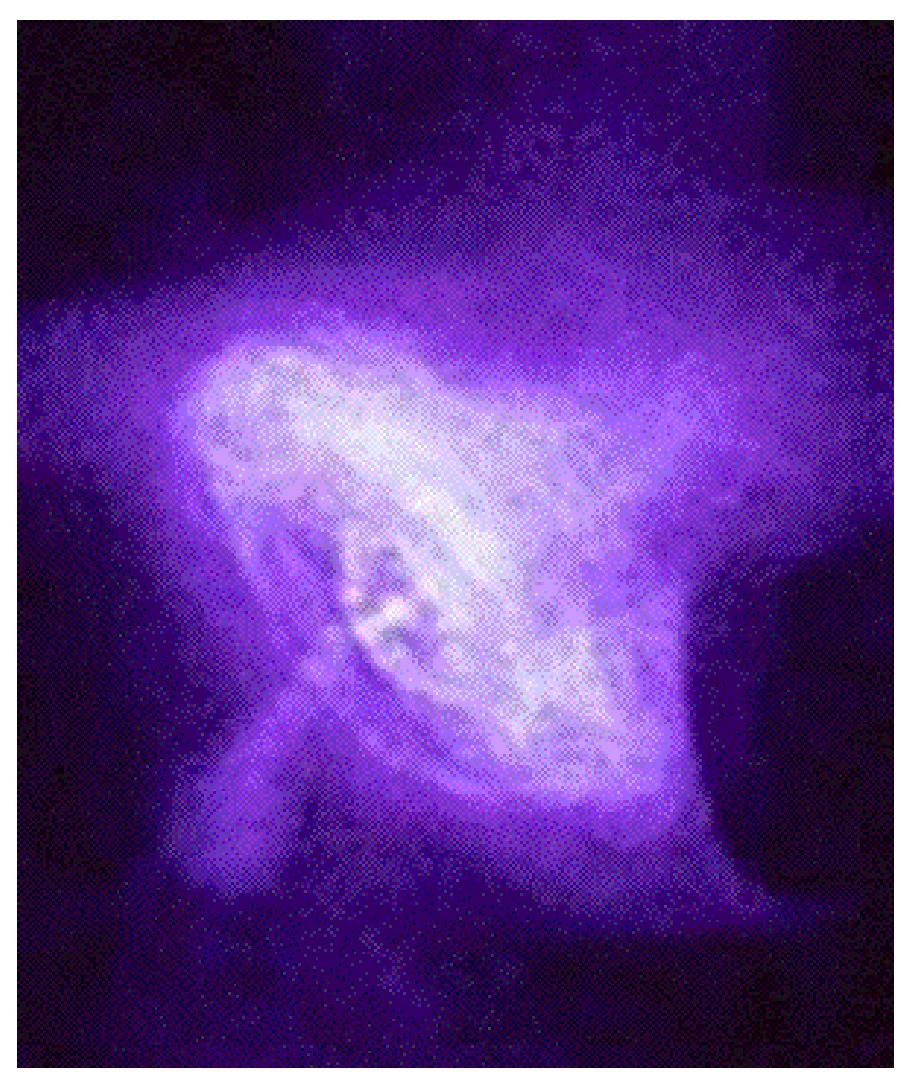

Figure 4:-Neutron repulsion in the Sun's core made our elements, birthed the solar system five billion years (5 Ga) ago, sustained the origin and evolution of life on Earth after $\sim 3.8 \mathrm{Ga}$ ago, causessolar eruptions and climate change (Carrington, 1859; Manuelet al., 2002; Karoffet al., 2016), and may even generate the force field that holds spinning sub-atomic particles together as atoms (Planck, 1944; Jenkins and Fischbach, 2009).

\section{Conclusions:-}

Neutron repulsion is the strong nuclear force that Aston (1922) probably envisioned offering the human race command over "powers beyond the dreams of scientific fiction. 'The impact on the human psyche of knowing that we really live only $1 \mathrm{AU}$ (astronomical unit) away from the powerful pulsar shown in Figure 4 is beyond the author's comprehension, but that knowledge has greatly improved the author's appreciation for earlier scientific and spiritual insights into mankind's place in the universe.

\section{Acknowledgments:-}

The author acknowledges with deep gratitude helpful hints in Kuroda's autobiography about possible errors in the developments of conceptsin nuclear energy in 1936-1949 (Kuroda, 1992), and the encouragement from other scientiststo explainto the public concisely why neutron repulsion was overlooked, especially to two leaders of the geo-ethics community - Professor Nils-Axel Mörner and Professor VáclavNěmec.

\section{References:-}

1. Anderson, H., Fermi, E. and Szilard, L. (1939): Neutron production and absorption in uranium. Physical Review, 56: 284-286.

2. Aston, F.W. (1922): Mass spectra and isotopes, Nobel Prize Lecture: pp. 1-20. The quote is from page 20.

3. Bethe, H.A. and Bacher, R.F. (1936):Nuclear physics A: Stationary states of nuclei. Reviews of Modern Physics, 8: 82-229.

4. Bohr, N. and Wheeler, J. A. (1939): The mechanism of nuclear fission. Physical Review, 56: 426-450.

5. Carrington, R.C. (1859): Description of a singular appearance seen in the Sun on September 1, 1959. Monthly Notices of the Royal Astronomical Society, 20: 13-15.

6. Chadwick, J. (1932): The existence of the neutron. Proceedings Royal Society London A: Mathematical, Physical and Engineering Sciences, 136: 692-708 
7. Einstein, A. (1905):ZurElektrodynamikbewegterKorper. Annalen der Physik17: 891-921; Ist die TrägheiteinesKörpers von seinemEnergie-gehaltabhängig?.ibidem,18: 639-641.

8. Hagiwara, T. (1939): Liberation of neutrons in the nuclear explosion of uranium irradiated by thermal neutrons. The Review of Physical Chemistry of Japan, 13: 145-150.

9. Hahn, O. and Strassmann, F. (1939): Über den Nachweis und das Verhalten der bei der Bestrahlung des UransmittelsNeutronenentstehendenErdalkalimetalle.Naturwissenschaften, 27: 11-15.

10. Halban, H.v., Joliot, F. and Kowarski, L. (1939): Liberation of neutrons in the nuclear explosion of uranium. Nature, 143: 470-471; Number of neutrons liberated in the nuclear fission of uranium. Nature, 143: 680-680.

11. Halban, H.v., Kowarski, L. and Savitch, P. (1939): Sur la capture simple des neutrons thermiques et des neutrons de resonance par l'uranium. C.R. Acad. Sci., 208: 1396-1398.

12. Jenkins, H. and Fischbach, E. (2009): Perturbation of nuclear decay rates during the solar flare of 13 December 2006. Astro-particle Physics 31: 407-411.

13. Karoff, C. Knudsen, M.F., Cat, P.D., Bonanno, A., Fogtmann-Schulz, A., Fu, J., Frasca, A., Inceoglu, F., Olsen, J., Zhang, Y., Hou, Y., Wang, Y., Shi, J. and Zhang, W. (2016): Observational evidence for enhanced magnetic activity of super-flare stars. Nature Communications, 7: doi:10.1038/ncomms11058

14. Kuroda, P.K. (1982):The Origin of the Chemical Elements and the Oklo Phenomenon. Springer-Verlag, Berlin, 165 pages. Thequote is from last line of page 2 .

15. Kuroda, P.K. (1992): My Early Days at the Imperial University of Tokyo, 1936-1949. University of MissouriRolla (Editor, O. Manuel) $69 \mathrm{pp}$. The quote is from page 7.

16. Manuel, O., Bolon, C., Katragada, A., and Insall, M. (2000): Attraction and repulsion of nucleons: Sources of stellar energy. Journal of Fusion Energy, 19: 93-98.

17. Manuel, O.K., Ninham, B.W. and Friberg, S, E. (2002): Super-fluidity, solar eruptions and climate. Journal of Fusion Energy, 21: 193-198.

18. Manuel, O.K. (2016a): Solar energy. International Education \& Research Journal,2 (5): 30-35.

19. Manuel, O.K. (2016b): Neutron repulsion - powers beyond the dreams of scientific fiction. International Education \& Research Journal,2(8): 43-45.

20. Planck, M. (1944). Das Wesen der Materie (The essence of matter). ArchivzurGeschichteder Max-PlanckGesellschaft, AbtVa, Rep 11 Plank, Nr. 1797. Quoted in modern references to the field that connects all thingsby Greg Braden: http://www.greggbraden.com/resources

21. Weizsäcker, C. F. v. (1935): ZurTheorie der Kernmassen, ZeitschriftfürPhysik A: Hadrons and Nuclei, 96: 431458.

22. Zinn, W. H. and Szilard, L. (1939). Emission of neutrons by uranium. The Physical Review, 56: 619-624. 